\title{
Diagnostics of railway turnout systems using tools of centralization blocking system
}

\author{
Ivan Siroklyn", Serhii Zmii, Artem Maslii, and Serhii Buriakovskyi \\ Ukrainian State University of Railway Transport, Feierbakh Square 7, 61050, Kharkiv, Ukraine
}

\begin{abstract}
Turnout systems are one of the few most important components of the railway infrastructure. Recently there has been a revival of research aimed at prognostics and health management of railway turnout systems. The works of the researchers are devoted to evolution timely diagnosis of damage of mechanical components or failures electrical components of switch motor, and contaminated by turnout system. In this article, the approaches of the most common specialized systems of diagnosing and predicting the technical condition of railway turnout systems elements such as POSS, SIDIS W, and APK-DK. The work presented in this article are followed by available approaches and studies of centralization blocking system tools' informativeness in the field of turnout systems failure diagnostic. The main point of view are methods of engine current analysis. The analysis of the motor current curves of the railway turnout obtained by the experimental method for different values of the ADC operating frequency is presented. Similar current curves are obtained by mathematical modeling of the normal operating mode of the elements of the railway turnout and under the condition of working with developing damage.
\end{abstract}

\section{Introduction}

An analysis of recent works in terms of diagnosis and prediction of the technical state of the railway turnout's elements indicates an increase of interest in this topic [1]. In [2] is shown, that $19 \%$ of all cases of train delays in Germany are related to switches' denials.

The possibility of contamination and other failures prediction for a railway switches was investigated in paper [3,4]. For determination of the most effective degradation indicators five different type of sensors are used [4] (force, current, voltage, linear speed and distance sensor). However, the mathematical model of object was not investigated, and the experiment concerned only the contamination. The more extensive researches in the field of turnout systems diagnosis, based on analysis of power curve which is consumed by the engine during a switch passing is shown at [4-10]. For the most part, a time analysis of the curve and power levels are used in studies and the failure prediction has been neglected.

Turnout system failures can be divided into two categories: mechanical failures and electrical ones. The first category includes degrading of switches, stockrails, condition of slide chair and other failures of elements related to the track-and-field economy. Second

* Corresponding author: seroklin.iv@gmail.com 
category includes failures of switch motor and its elements. The analysis of security divisions of railway transport of Ukraine shows that the share of the first category account for about $53 \%$ of turnoute systems damage.

According to switches of the track 1520 and the most common switch motors with engine MSP and MST types there are a number of works, which describe the diagnostic signs of damages [8]. Diagnostic signs of deterioration of the technical condition of the main elements separately for the mechanical part of the railway turnout are presented in Table 1.

Table 1. Diagnostic signs of railway turnout systems damage.

\begin{tabular}{|l|l|}
\hline \multicolumn{1}{|c|}{ Failures } & \multicolumn{1}{c|}{ Diagnostic signs } \\
\hline $\begin{array}{l}\text { Absence of distance in the heel } \\
\text { spread }\end{array}$ & $\begin{array}{l}\text { Gradual or sharp increase in the } \\
\text { amplitude of the signal (current) at the } \\
\text { end of the time dependence }\end{array}$ \\
\hline $\begin{array}{l}\text { Shift of stockrails and/without } \\
\text { clamp of switch under the stockrail }\end{array}$ & $\begin{array}{l}\text { Gradual or sharp increase in the } \\
\text { amplitude of the signal (current) at the } \\
\text { end of the time dependence }\end{array}$ \\
\hline Contaminated slide chair & $\begin{array}{l}\text { Gradual accretion of the current } \\
\text { amplitude during each subsequent pass of } \\
\text { switches }\end{array}$ \\
\hline $\begin{array}{l}\text { Contaminated turnout system of } \\
\text { loose materials }\end{array}$ & $\begin{array}{l}\text { Curt accretion of the current amplitude } \\
\text { during the pass of the current switch } \\
\text { compared with previous one }\end{array}$ \\
\hline Slacks on connecting rods & $\begin{array}{l}\text { Operating time increasing before } \\
\text { switches start moving. Increasing of the } \\
\text { operating time in general }\end{array}$ \\
\hline
\end{tabular}

\section{Specialized systems for diagnosing the technical state of the turnout system elements}

In Europe there are several systems which are capable to diagnose failures of turnout systems: Roadmaster 2000 (VAE), POSS (Strukton), and SIDIS W (Siemens). In POSS systems (Germany, Netherlands) a fairly simple approach is used in which, each time the switch is moved, the charts of the main power parameters changes are formed and compared with the reference for a particular switch [9]. The SIDIS W system uses the proportionality ratio between the switch shift effort and the active power consumed by the engine. The change in active power curve whilst moving the switch is used to diagnose bounce. It was the data of the SIDIS W system used in [2] to analyze the most efficient mathematical model of the prediction. The paper substantiates the expediency of choosing an interval of 3-5 days to warn staff of the high likelihood of occurrence of a particular type of failure (RUL). The basis for failure prediction is the principle of monitoring the power level, time characteristics of the signals and the climatic parameters has been taken into account. According to the author's assurances, the best methods for predicting the residual resource allowed to predict about $50 \%$ of documented failures.

On the territory of Ukraine, "Kaskad", "Prohnoz", "APK-DK", "ASDK" systems are operated. In one way or another, they provide information on the operating modes of drives, but information is stored only in the form of discrete signals. The market offers "APK-DK" system, which is specially designed for diagnostics of the elements of the switch according to the current curve. The ability to store an analog signal (for example, motor current curves) is only available in new microprocessor centralization blocking systems. Intelligent processing in the part of the system is performed for diagnostic tasks mostly often in the 
form of exceeding control for the maximum permissible value of current (or power), or identification of engine operation on friction. The system of electricity supply control, which, as a rule, is an integral part of the equipment of the centralization blocking system, continuously records the main parameters.

In addition to the analysis of currents levels, in work [8] the synthesis of two other approaches in the diagnostics of the electric drive: time principles and spectral ones are proposed, where it is proposed to analyze the spectrum within the first five harmonics.

\section{Control of the current curve by means of centralization blocking systems}

Most centralization blocking systems produced in Ukraine use controllers of switches, which are capable of removing the current values of an engine with a period which is close to $1 \mathrm{~ms}$. he step (quantum) of fixation with the value of current is less than $0.01 \mathrm{~A}$. For comparison, the specialized system of diagnostics of the railway turnout systems "APK$\mathrm{DK}$ " uses the ADC with a period of $0.001 \mathrm{~s}$ but averages the values of ten measurements to reduce the nuisance impact. Thus the informative period is $0.001 \mathrm{~s}$. However, in centralization blocking systems, the main limiting factor is not the parameters of the ADC of the object controller, but the data transmission network to the central processor of the system. Bandwidth of a network of existing systems rarely uses a period of 0.05 with more frequent use of $0.1 \mathrm{~s}$ or $0.4 \mathrm{~s}$. For analyzing the informativity of measurements in laboratory conditions, with digital measurement means, the current curve with a period of $0.001 \mathrm{~s}$ was removed and the average value of the current of each 10 measurements was calculated. (Curve a), Fig. 1). The average of ten measurements of the current curve with a period of $0.02 \mathrm{~s}, 0.05 \mathrm{~s}$ and $0.1 \mathrm{~s}$ were made (Curves b), c) and d), Fig. 1). By expression a), the value of the mean-square deviation of the current values of curves b), c) and d) from curve 1 is calculated, which is taken as the reference:

$$
\sigma^{2}=\sum_{n=1}^{j}\left(A_{n}^{\prime}-A_{n}^{\prime \prime}\right)^{2},
$$

where $\sigma$ - the mean-square deviation of the results of measurements of the values of the engine current at the measuring unit $\mathrm{n}, j$ - number of measurements for constructing the current curve, $A_{n}^{\prime}-$ value of the current of the reference curve at the measuring unit $\mathrm{n}$, $A_{n}^{\prime \prime}$ - value of the current curve at the n-measurement.

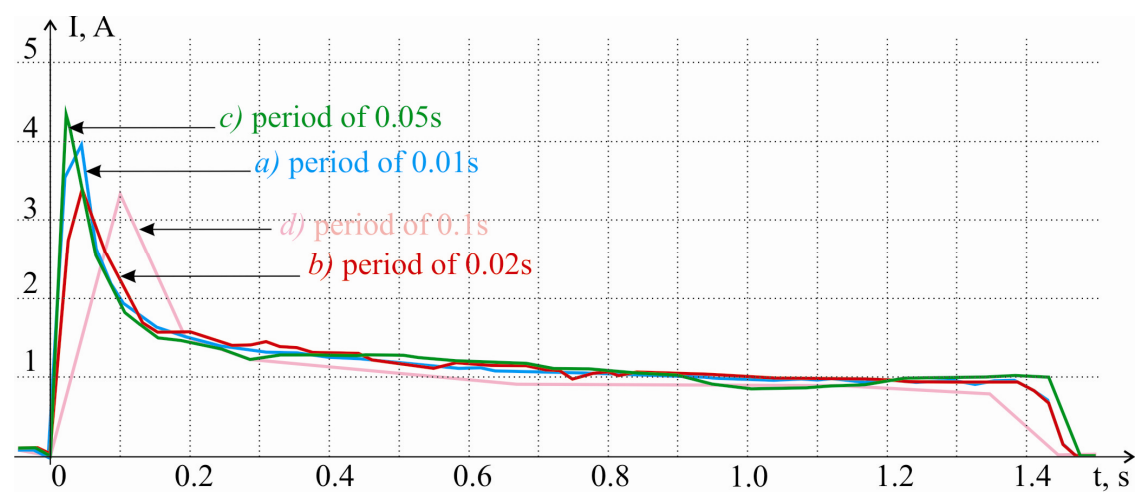

Fig. 1. Measurements of the current in laboratory conditions. 
Using the methods of linear extrapolation and interpolation, the number of points of current measurements $(j)$ on which the deviation was calculated is taken $j=71$ with a uniform distribution along the curve. The results of calculating deviations of values from the reference are presented in Table 2. One can see that the deviation is not significant, given the fact that for the diagnosis the deviation of the values of the controlled value by $10 \%$ or $20 \%$ will be informative.

Table 2. Results of calculating deviations of values from the reference.

\begin{tabular}{|c|c|c|c|c|}
\hline Period of measurements, c & 0.01 & 0.02 & 0.05 & 0.1 \\
\hline $\begin{array}{c}\text { Medium-square deviation of } \\
\text { results, A }\end{array}$ & - & 1.102 & 1.26 & 3.341 \\
\hline
\end{tabular}

\section{Theoretical studies}

For theoretical studies, a mathematical model of the operation of switching was used [10]. Particular attention was paid to the description of the turnout kinematic line in the nature of the movement of the switch points, as the 3 masses mechanical system. Since the process of transformation of the energy of an electric field into a rotating moment on a machine shaft (and, consequently, in the motion of a working body) is interconnected, the junction was considered as a single electromechanical system. In Fig. 2 shows the diagram of the motor current in the absence of load.

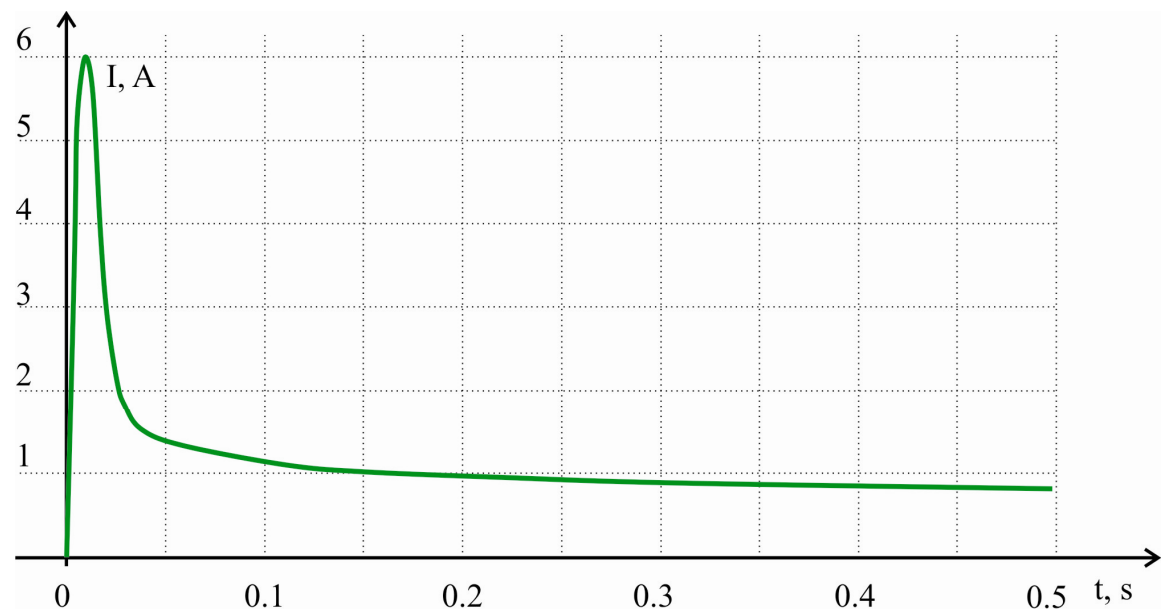

Fig. 2. Diagram of motor current without load

Load parameters - the weight of the switch points and the strength of their resistance to movement during the transfer, as well as the features of the turnout work (for example, operating mode at contaminated transfer surfaces or other faults) affect the electric engine, which, in turn, changes any processes affects the nature of the movement of rails. On the mathematical model [10] an experiment was conducted in the mode of contaminated transfer surfaces. From the current diagram (Fig. 3) it is clear that exactly this factor causes a variation of the force that affects the engine current. In this case, the frequency of such oscillations is within $70-100 \mathrm{~Hz}$. That is, to imagine the behavior of the motor current, it is desirable to measure its dimensions with a frequency of not less than $1 \mathrm{kHz}$. 


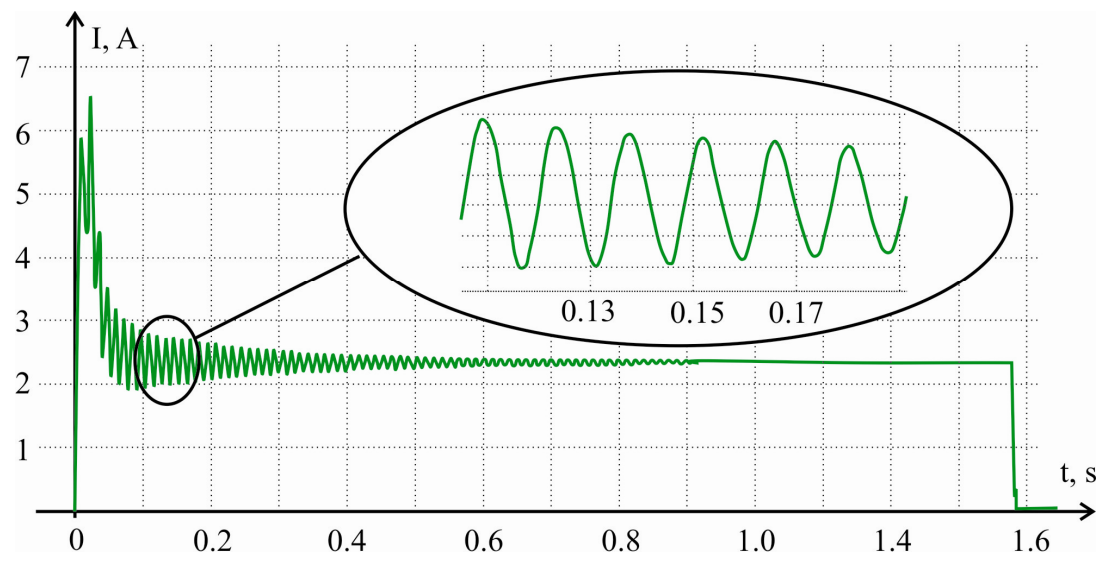

Fig. 3. Diagram of engine current during transfer with contaminated transfer surfaces

\section{Conclusions}

Available technical means of modern centralization blocking systems enable to realize the functions of diagnostics of the technical condition of switching elements using methods of analysis of the current curve of the electric drive motor. This relates to controlling the current level, character, and time of the switch transition.

In most cases, the bandwidth of data transmission systems restricts the use of some of the methods requiring an increase in the frequency of measurements. As a way out of the situation, one can propose to consider the option of embedding diagnostics in general, or certain types of diagnostics on the object controller itself, with the transfer of the signs of the switch technical state to the CPU of the codes system.

\section{References}

1. V. Atamuradov, K. Medjaher, P. Dersin, B. Lamoureux, N. Zerhouni, Int. J. of PHM, 060, 1-31 (2017)

2. T. Bohm, Int. J. of PHM, 059, 1-15 (2017)

3. U. Oßbergera, W. Kollment, S. Eck, Procedia Structural Integrity, 4, 106-114 (2017)

4. F. Camci, O. Faruk Eker, S. Başkan, S. Başkan, Proceedings of the Institution of Mechanical Engineers, Part F: Journal of Rail and Rapid Transit, 230, 24-42 (2016)

5. V. Atamuradov, F. Camci, S. Baskan, M. Sevkli, Ieee international symposium on diagnostics for electric machines, power electronics and drives, Piscataway (NJ ), 1-5 (2009)

6. O. Eker, F. Camci, U. Kumar, U. Kumar (Ed.), emaintenance Lulea (Sweden): Univ, 248-251 (2010)

7. T. Asada, C. Roberts, T. Koseki, Transportation Research Part C: Emerging Technologies, 30(0), 81-92 (2013)

8. S.Iu. Buriak, V.I. Havryliuk, O.A. Hololobova, Bulletin of the Dnipropetrovsk National University of Railway Transport, 4 (58),7-25 (2015)

9. K. Seidl, Signal + Draht, 12, 39-40 (2003)

10. S.H. Buriakovskyi, A.S. Maslyi, Bulletin of the National Technical University "Kharkiv Polytechnic Institute", 28, 392-393 (2010) 